\title{
Effect of GHR variation on mandibular height
}

\author{
Arief Johanes Halim ${ }^{1}$, Elza Ibrahim Auerkari ${ }^{2 *}$ \\ ${ }^{1}$ Orthodontic Residency Program, Faculty of Dentistry, University of Indonesia, Jakarta 10430, \\ Indonesia \\ ${ }^{2}$ Department of Oral Biology, Faculty of Dentistry, University of Indonesia, Jakarta 10430, \\ Indonesia \\ *Email: elza.ibrahim@ui.ac.id
}

\begin{abstract}
Growth hormone (GH) is a hormone produced by the acidophil of the anterior pituitary gland that affects the growth and development of craniofacial structures. GH must bind to the growth hormone receptor (GHR) to stimulate the target site. As GH is the primary regulator of bone growth, the GHR plays an important role in determining morphological traits. The GHR is also found in the condyle region. Few studies have examined the correlation between variation in the GHR and mandibular height in Korean, Japanese, and Han Chinese populations. These studies showed that amino acid substitutions at P561T, C422F, and 1526L were correlated with mandibular height. Various environmental factors contribute to mandibular morphogenesis, but we know that genetic factors also play a considerable role. Previous studies revealed correlations between genetic variants of GHR and mandibular morphogenesis. Knowledge of the genetic markers involved in craniofacial morphogenesis will allow clinicians to more easily predict orthopedic reactions in advance of treatment.
\end{abstract}

Keywords: growth hormone receptor, mandibular height, orthopedic reactions, advance of treatment

\section{Introduction}

Growth hormone $(\mathrm{GH})$ is a hormone produced by the acidophils of the anterior pituitary gland that affects the growth and development of craniofacial structures. GH must bind to the growth hormone receptor (GHR) to stimulate the target site. The chromosomal location of the GHR gene is $5 \mathrm{p} 13.1-\mathrm{p} 12$. It is $87 \mathrm{~kb}$ in length and comprises 10 exons. To induce bone formation, GH must bind to the target organ, in growth plates, and in mesenchymal cells [1-3].

Binding of GH to the GHR in the growth plate stimulates endochondral ossification at that site. Targeting by GH causes the liver to produce insulin-like growth factor-1 (IGF-1). IGF-1 induces osteoblast formation, osteoclastogenesis, and mature osteoclast activity, which will result in increased bone formation. Finally, GH stimulates mesenchymal cells to proliferate [1].

In the mandibular condyle, external stimuli, such as repositioning of the condyle and differentiation of mesenchymal cells that will proliferate and mature, activates chondrogenesis. An increase in GH will stimulate IGF-1 synthesis, increasing mitotic activity [1]. Condylar cartilage is a secondary cartilage that can also be stimulated to grow by mechanical means. For example, the orthodontist usually uses a 
mandibular positioning appliance in mandibular deficiency to help stimulate mandibular growth [4-6].

Some unique craniofacial configurations have been reported in children with growth hormone deficiency (GHD) [7]. People with GHD experience restricted growth and are usually of short stature [8]. An underdeveloped mandible could sometimes result in obstructive sleep apnea (OSA) because of airway constriction $[9,10]$. The prevalence of OSA is $3 \%-35 \%$ for children younger than 13 years, and the mortality rate is $15 \%$, mainly because of airway blockage due to underdeveloped mandible [11].

The effect of GHD on craniofacial morphology manifest in the small size of the anterior and posterior cranial base. In the lower jaw segment, GHD results in low posterior facial height and low posterior mandibular height [12]. In several studies GHR variations were related to mandibular height in Japanese, Chinese, and Korean populations [13-16]. In GHR knockout mice, the mandibular ramus height was reduced, and the femur:crown-rump and femur:tibia ratios were decreased $[17,18]$. This paper aimed to identify the gene responsible for craniofacial phenotypes to facilitate better diagnosis and treatment plans for patients with cranial malformations, for example, mandibular retrognathism

\section{GHR polymorphisms in the Korean population}

Kang et al. (2009) sought a correlation between variations in GHR and craniofacial morphology. They studied five SNPs in exon 10 of the GHR in 159 Koreans craniofacial morphology. Out of 159 unrelated subjects, 100 were men and 59 were women. Those with congenital disorders (e.g., cleft palate or systemic diseases) were excluded [13].

He performed PCR and measured craniofacial morphology by lateral cephalogram. He measured cranial based length (Nasion-Sella, N-S), maxillary length (Point A-Pterigo Maxilarry Fissure), overall mandibular length (Gnathion-Condly, Gn-Co), mandibular corpus length (Pogonion-Gonion, Pog-Go), and mandibular ramus height (Condyl- Gonion, Co-Go) [13].

This research showed an association between P561T and C422F SNPs of the GHR locus in the Korean population. Haplotype analysis indicated that people with haplotype-4 differed significantly from those without haplotype-4 in terms of mandibular ramus height [13].

In support of the above findings, Kang et al. (2009) revealed associations between the P561T and C422F polymorphisms in the GHR and mandibular ramus height in a sample Japanese population [13-15]. However, in contrast to the findings of Zhou, Kang et al. found no correlation between mandibular ramus height and the I526L polymorphism $[13,16]$.

\section{GHR polymorphisms in the Japanese Population}

The rate of heterozygosity for the mutation Pro561Thr exceeds 10\% in the Japanese population. For this reason, Yamaguchi et al. (2001) conducted a study to determine the correlations between the Pro561Thr variant of the GHR and craniofacial morphology in a sample Japanese population [15]. 
The study sample included 50 Japanese men and 50 Japanese women, and those with congenital disorders (cleft palate or systemic diseases) were excluded. The lateral cephalogram was taken for analysis of craniofacial morphology. The reference points were cranial base length (Nasion-Sella), maxillary length (Point A-Pterigo Maxilla Fissure), mandibular ramus length (Condyl-Gonion), and mandibular corpus length (Condyl-Gnathion) (Fig. 1) [15].

The results of this study indicated that presence of the Pro561Thr substitution was correlated with the length of the mandibular ramus but not with other craniofacial morphology parameters. Their conclusion was that the P561T gene variant was associated with a shorter mandibular ramus in the normal Japanese population [15].

Tomoyasu et al. (2007) studied 167 Japanese subjects (a larger sample size than that in the study by Yamaguchi et al.) on the association between 5 SNPs: C422F, S473S, P477T, I526L, and P561T in exon 10 of the GHR gene and craniofacial morphology. Tomoyasu et al. showed correlations between the P561T and C422F variants and mandibular ramus height in Japanese subjects, confirming the findings of Yamaguchi et al. but contradicting those of Zhou et al. [14,15] Subjects with genotype CC in P561T and genotype GG in C422F had greater mandibular height than those with genotypes CA and GT.

\section{GHR polymorphisms in the Han Chinese Population}

In the Japanese population, the only correlations were found with the P561T and C422F GHR variants, which differed from the findings of Zhou at al. in the Chinese population. Zhou et al. (2014) studied the correlation of mandibular height with GHR variations in 145 subjects [16]. The results of this study differed from the findings in Korean and Japanese populations. A correlation was found between mandibular ramus height (S-Go) and the variant I526L, and no correlation was found between C422F, G168G, and P561T and any of the measurement parameters. Individuals with genotype $\mathrm{CC}$ have longer rami than those with the genotype $\mathrm{AC}$ or AA for the GHR I526L variant [16].

\section{Epigenetics}

Epigenetics is the study of changes in gene function that are not induced by changes in DNA sequence. Epigenetic mechanisms are under environmental influence and include DNA modification, histone modification, and post-transcriptional silencing by RNA interference, which can activate or inactivate the gene [19].

$\mathrm{GH}$ therapy is one of the environmental factors that could affect mandibular height; if administered for more than 2 years, it may result in increased growth of the craniofacial skeleton. This therapy will induce cartilage growth that can be detected by the Condyle-Gonion measurement. This may increase craniofacial development, which will affect occlusion and the facial profile [20].

Morishima et al. (1995) stated that genetic and environmental factors exert smaller effects than sex hormones on bone and muscle development [21]. Fujita et al. (2004) reported that craniofacial development could be reduced by suppressing sex hormones during the pubertal growth phase in experimental studies [22]. Another study on the correlation between sex hormones and mandibular growth was 
carried out by Fujita et al. (2006). They showed that a deficiency of sex hormones will change the internal structure of the condyle and indicated that sex hormones are key determinants of mandibular growth and development [23].

\section{Conclusion}

Various environmental factors contribute to mandibular morphogenesis, but genetic factors also play a critical role. The few studies cited above showed that correlations exist between genetic variations in the GHR (C422F and P561T) and mandibular height (Co-Go) in Japanese and Korean populations [13-15]. In a sample Chinese population, a correlation was found between the GHR I526L variant and the mandibular ramus height [16].

Even though the results in a Chinese population differed from those in Japanese and Korean populations, the results of these studies suggest relationships between mandibular ramus length and GHR. The above-mentioned studies also did not find any correlation between SNPs and mandibular length (Co-Gn and Go-Pog or overall mandibular length (Co-Gn, Ar-Gn and Ar-Pog) [13-16].

By knowing the genetic markers of craniofacial morphogenesis, we as clinicians can more easily predict an orthopedic reaction in advance of treatment. For example, if the patient has a GHR variant that is associated with lower mandibular height, we could plan to stimulate mandibular growth using functional equipment such as a facemask, headgear, and Herbst appliances [24].

\section{References}

1. Litsas G. Growth hormone and craniofacial tissues. An update. Open Dent J. 2015; 9:18 .

2. Leung DW, Spencer SA, Cachianes G, Hammonds RG, Collins C, Henzel WJ, Barnard R, Waters MJ, Wood WI. Growth hormone receptor and serum binding protein: purification, cloning and expression. Nature. 1987;330(6148):537-543.

3. Giustina A, Mazziotti G, Canalis E. Growth hormone, insulin-like growth factors, and the skeleton. Endocrine Rev. 2008;29(5):535-59.

4. Sobue T, Yeh WC, Chhibber A, Utreja A, Diaz-Doran V, Adams D, Kalajzic Z, Chen J, Wadhwa S. Murine TMJ loading causes increased proliferation and chondrocyte maturation. J Dent Res. 2011;90(4):512-6.

5. Oyonarte R, Zárate M, Rodriguez F. Low-intensity pulsed ultrasound stimulation of condylar growth in rats. Angle Orthodont. 2009;79(5):964-70.

6. Rabie AB, Hägg U. Factors regulating mandibular condylar growth. Am J Orthodont Dentofac Orthoped. 2002;122(4):401-9.

7. Pirinen S, Majurin A, Lenko HL, Koski K. Craniofacial features in patients with deficient and excessive growth hormone. J Craniofac Gen Development Biol. 1994;14(3):144-52.

8. Ranke MB, Bierich JR. 4 Treatment of growth hormone deficiency. Best Practice \& Res Clin Endocrinol Metabol. 1986;15(3):495-510.

9. Sunitha C, Kumar SA. Obstructive sleep apnea and its management. Indian J Dent Res. 2010;21(1): 119.

10. Chang ET, Shiao GM. Craniofacial abnormalities in Chinese patients with obstructive and positional sleep apnea. Sleep Med. 2008;9(4):403-10. 
11. Lavie $P$, Herer $P$, Lavie L. Mortality risk factors in sleep apnoea: a matched case-control study. J Sleep Res. 2007;16(1):128-34.

12. Khare SK, Gupta R, Prakash A. Endocrine disorders and their effects in orthodontics. Int J of Medical Dent Sci. 2013;3(4):280-5.

13. Kang EH, Yamaguchi T, Tajima A, Nakajima T, Tomoyasu Y, Watanabe M, Yamaguchi M, Park SB, Maki K, Inoue I. Association of the growth hormone receptor gene polymorphisms with mandibular height in a Korean population. Arch Oral Biol. 2009;54(6):556-62.

14. Tomoyasu Y, Yamaguchi T, Tajima A, Nakajima T, Inoue I, Maki K. Further evidence for an association between mandibular height and the growth hormone receptor gene in a Japanese population. Am J Orthodont Dentofac Orthoped. 2009;136(4):536-41.

15. Yamaguchi T, Maki K, Shibasaki Y. Growth hormone receptor gene variant and mandibular height in the normal Japanese population. Am J Orthodont Dentofac Orthoped. 2001;119(6):650-3.

16. Zhou J, Lu Y, Gao XH, Chen YC, Lu JJ, Bai YX, Shen Y, Wang BK. The growth hormone receptor gene is associated with mandibular height in a Chinese population. J Dent Res. 2005 Nov;84(11):1052-6.

17. Sjögren K, Bohlooly YM, Olsson B, Coschigano K, Törnell J, Mohan S, Isaksson OG, Baumann G, Kopchick J, Ohlsson C. Disproportional skeletal growth and markedly decreased bone mineral content in growth hormone receptor-/- mice. Biochem Biophys Res Com. 2000 Jan 19;267(2):603-8.

18. Ramirez-Yañez GO, Smid JR, Young WG, Waters MJ. Influence of growth hormone on the craniofacial complex of transgenic mice. Eur J Orthodont. 2005;27(5):494-500.

19. Lambert MP, Herceg Z. Mechanisms of Epigenetic Gene Silencing, Epigenetic Aspects of Chronic Diseases. London: H.I Roach, F. Bronner \& R.O.C. Oreffo. Spinger; 2011.

20. Funatsu M, Sato K, Mitani H. Effects of Growth Hormone on Craniofacial Growth: Duration of Replacement Therapy. Angle Orthodont. 2006;76(6):970-7.

21. Morishima AK, Grumbach MM, Simpson ER, Fisher C, Qin KE. Aromatase deficiency in male and female siblings caused by a novel mutation and the physiological role of estrogens. J Clin Endocrinol Metabol. 1995 Dec 1;80(12):3689-98.

22. Fujita T, Ohtani J, Shigekawa M, Kawata T, Kaku M, Kohno S, Tsutsui K, Tenjo K, Motokawa M, Tohma Y, Tanne K. Effects of sex hormone disturbances on craniofacial growth in newborn mice. J Dent Res. 2004 Mar;83(3):250-4.

23. Fujita T, Ohtani J, Shigekawa M, Kawata T, Kaku M, Kohno S, Motokawa M, Tohma $\mathrm{Y}$, Tanne K. Influence of sex hormone disturbances on the internal structure of the mandible in newborn mice. Eur J Orthodont. 2006 Jan 13;28(2):190-4.

24. Mitchell L. An introduction to orthodontics. Oxford University Press; 2013 Jan 24. 